\title{
El teatro en Buenos Aires en el invierno austral del 2007
}

\section{María Silvina Persino}

Esto será necesariamente una visión parcial de la enorme oferta teatral que produce Buenos Aires en invierno. De los muchos espectáculos que vi, he seleccionado unos pocos que serán la base de este artículo. Una vez más, dejo fuera el teatro comercial aunque, de acuerdo con las críticas y los comentarios escuchados, cobija algunas propuestas de calidad, tales como Soy mi propia mujer, protagonizada por Julio Chávez, o Camino a la meca, con la veterana actriz uruguaya China Zorrilla. Esta vez no me interesaron especialmente las propuestas del teatro oficial aunque, por muy pocos días, me perdí un promisorio estreno de La persistencia de Griselda Gambaro, con dirección de Cristina Banegas, en el Teatro San Martín. De manera que mi registro se circunscribe esta vez al circuito off donde, como viene sucediendo desde hace unos años, había algunos espectáculos que seguían en cartel desde temporadas anteriores. Entre las obras que comentaré, tal es el caso de De mal en peor (Ricardo Bartís), La omisión de la familia Coleman (Claudio Tolcachir) y Un amor de Chajarí (Alfredo Ramos). Estos espectáculos tienen también en común el hecho de que los directores son a la vez los encargados de la dramaturgia. Se trata de un tipo de trabajo en el que a partir de ideas germinales, el texto va tomando forma final en las improvisaciones de los actores y el trabajo de ensayo en general. Sin embargo, a diferencia de otras creaciones colectivas, en ningún momento aquí se tiene la sensación de que se está escuchando un texto aleatorio, errabundo, o de diálogo circunstancial. Por el contrario, hay frases memorables, diálogos de una riqueza muy cuidada, situaciones de humor derivadas del texto. Posiblemente se trata de las tres propuestas más atractivas, interesantes y logradas de la escena teatral porteña del momento.

En De mal en peor se presenta la decadencia de una familia de clase alta en el primer centenario de la independencia argentina (1910). ${ }^{1}$ 


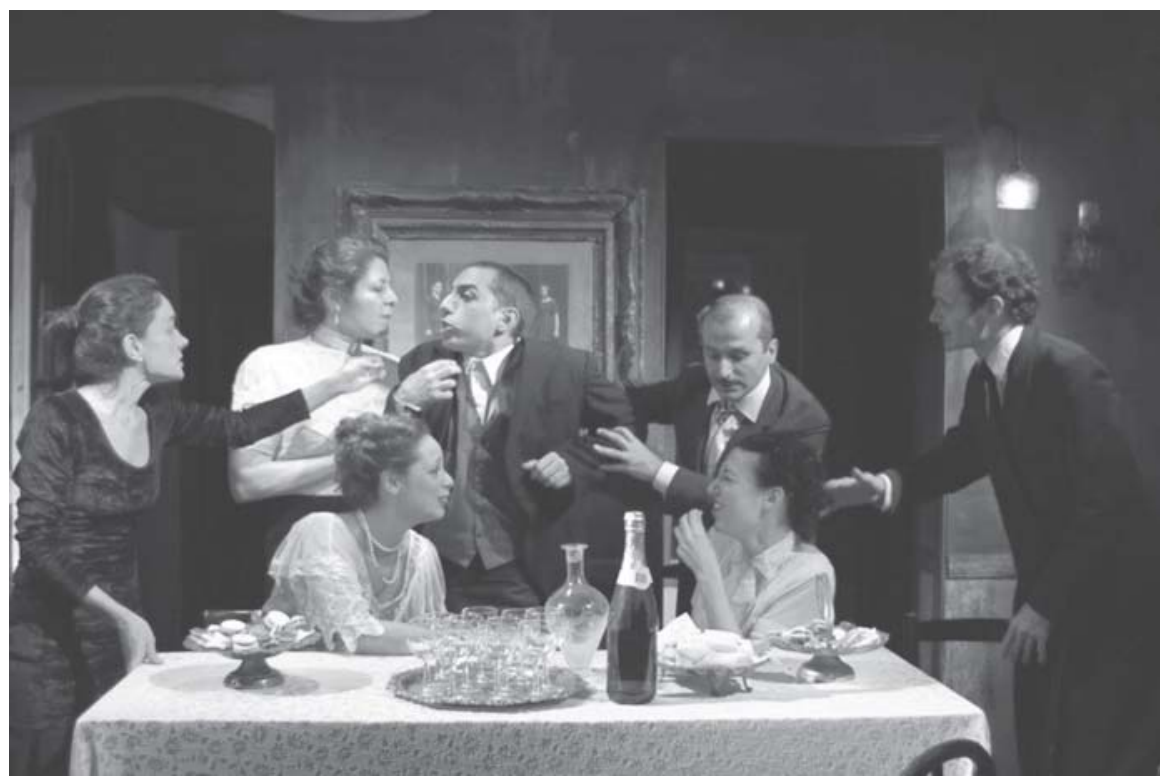

De mal en peor. Foto de Damián Nussembaum.

Además, a este contexto histórico preciso, se le suma la presencia de un personaje peculiar: una maestra estadounidense, de aquellas que trajo a Argentina el presidente Sarmiento en la década de 1860, y que tras ser secuestrada por los indios, ya anciana, es "recuperada" para la civilización. La familia queda a cargo de su protección y a cambio de eso, esperan encontrar los documentos que le otorgan una suma importante de dinero que el gobierno le ha concedido a modo de compensación. Las deudas están devorando a la familia, y el hallazgo del tesoro podría resultar la salvación familiar. Mientras, se van mostrando las rivalidades entre hermanos y hermanas, cuñados y cuñadas, sobrinos y sobrinas, todos viviendo bajo el mismo techo. La reconstrucción de época en los vestuarios, el lenguaje y los objetos escénicos están perfectamente logrados. Toda la acción transcurre no en lo que sería la sala del Sportivo Teatral, sino en las habitaciones de la casa que la anteceden. Los apenas 40 espectadores serán acomodados dentro de una de las habitaciones donde se moverán los actores, cuyas acciones pese a lo reducido del espacio - preservan una limpieza escénica admirable. Sin embargo, el espectáculo comienza antes y en otra habitación, ya que la familia ha encontrado una manera de lucrar con la historia de la vieja maestra, montando un pequeño museo con objetos de la cultura indígena y con la 
presencia de la mujer. Ya en la habitación donde transcurre la acción, la puesta en escena ha integrado los tres espacios de puertas que desembocan allí, y la galería donde por momentos algún personaje toca el piano. Ramiro (Carlos Defeo) se mueve entre la desesperación y la impunidad, y es uno de los personajes más interesantes, como uno de los patri familia sobre los que recae la responsabilidad de este singular grupo. También se destaca el trabajo de Claudia Cantero, en la compleja criatura de Regina, una mujer fuerte y dura, pero a la vez con una inmensa necesidad de amor erótico. En la estética escénica de Bartís, en la que el humor no está ausente, los conflictos son amplificados por una lente de aumento y los personajes actúan en un estado de crispación casi constante.

También La omisión de la familia Coleman se presenta en un lugar poco convencional: el estudio de su director, llamado Timbre 4, el departamento del fondo de un PH al que se accede por un pasillo, en el que se abren las puertas de otros departamentos. Aunque el ámbito que les queda a los actores es bastante más amplio que en el caso anterior, también aquí se aprovechan los espacios adyacentes, las puertas, y una escalera, que desembocan en la habitación. El juego inteligente y sugeridor con el espacio es uno de los grandes aciertos de la puesta. Inclusive lo que sucede en el baño, enfrente de la sala, es parte de la acción y se puede ver a través de un vidrio semiopaco. La familia Coleman está formada por varios hijos postadolescentes, de distintos padres, que conviven con su madre y la abuela, una especie de matriarca. Nada falta en el catálogo de la disfuncionalidad: abuso sexual, incesto, adulterio, abandono. Sin embargo, el humor permea toda la obra, y estos temas no se presentan en forma explícita ni son objeto de conversación; simplemente se van transparentando en las interacciones familiares. El personaje tal vez más inquietante es la madre (Miriam Odorico), una criatura que nunca ha madurado y que actúa en un estado de alegría irresponsable y amoral. Habiendo visto a Inda Lavalle en un papel completamente diferente en otro espectáculo de Tolcachir (Lisistrata) se hizo evidente el enorme talento de esta actriz que, en La omisión, encarna a la única integrante de la familia que parece haberse salvado de la catástrofe.

Alfonso Ramos, el director de Un amor de Chajarí, se formó como actor con Ricardo Bartís, actuó en Postales argentinas y en El pecado que no se puede nombrar (ambas dirigidas por Bartís). También colaboró dramatúrgicamente con él, de manera que la creación de Un amor de Chajari tiene definitivamente la impronta de quien es uno de los grandes maestros de actores en Buenos Aires. ${ }^{2}$ En efecto, el actor y las tres actrices 
de Un amor de Chajari han sido dirigidos por Ramos hacia un tipo de actuación que se aparta del naturalismo de un Julio Chávez (otro maestro de actores muy popular pero muy diferente), o de los códigos contenidos de algunas creaciones de Daniel Veronese. La dirección de Ramos les imprime a los personajes un código de desmesura que, sin embargo, no es permanente y se modula y dosifica a lo largo de la obra. La acción se sitúa en un ambiente rural, en la provincia de Entre Ríos, con la excelente escenografía de Félix Padrón, que construye el interior de una casa sumamente precaria. Ester, en silla de ruedas tras un accidente, está casada con Faustino, y ambos viven con la hermana soltera de Ester. Faustino admite haberse convertido en una bestia y como tal trata a las mujeres de su casa. Sus obsesiones son dos: conseguir descendencia y obtener petróleo de un pozo que se abre en la misma choza donde viven. A una y otra obsesión dedica la mayor parte de su tiempo. Estos dos objetivos en apariencia tan diversos, por momentos se tejen de manera delirante en una imaginería común, en la que bombear el semen de Faustino o el petróleo del pozo se entrelazan como destinos de salvación. Toda la obra está recorrida por una fuerte dosis de humor que en parte, para el espectador porteño, tiene que ver con el acento, la lengua y la tonada campesina y entrerriana que hábilmente recrean los actores. Pero sobre todo, y de manera creciente hacia el final de la obra, se trata de un intenso humor negro que se engarza con la estética grotesca que arma todo el espectáculo. Alfredo Ramos se encuentra en el proceso de ensayo de otro espectáculo, con algunos de estos excelentes actores, a los que se le sumarán otros. Se trata de un creador al que habrá que prestar mucha atención.

El experimento Damanthal, dirigido por Javier Margulis, se estrenó el 1999, fue seleccionado para el Festival Internacional de Teatro en Buenos Aires ese mismo año, y siguió intermitentemente en cartel hasta el 2001. Tras haber sido presentado en escenarios internacionales y en giras por el interior de Argentina, el espectáculo fue repuesto durante el mes de mayo de 2007 en el Centro Cultural Borges. Esta experiencia bella e inquietante forma parte de un teatro de imágenes, cuyos cultores actuales más destacados sean posiblemente el mismo Margulis y Omar Pacheco. Es para celebrar que las modas teatrales no impidieron el regreso de una obra que sigue provocando todavía el asombro, la reflexión y la fruición estética. La historia detrás de estas imágenes va siendo provista por voces en off - una predominante es una voz documental masculina - y surge de los experimentos médicos del neurólogo alemán nacido en 1843, Dr. Alfredo Damanthal. Este médico no tuvo escrúpulos en someter a seres humanos a crueles 


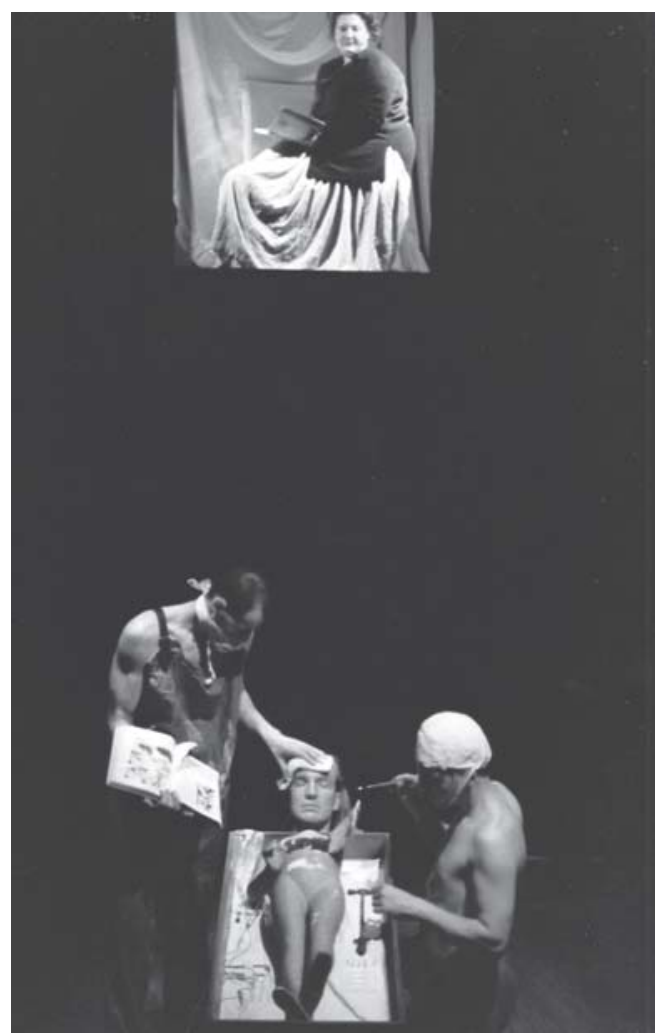

El experimento Damanthal. Foto de Pilar Castex.

experimentos con el fin de avanzar en su conocimiento científico. El hecho de mencionar una relación con Freud y con Jung, le da a esta biografía apócrifa un carácter real que los comentarios de los medios - con alguna excepción - no han desmentido, sino que han incluso ratificado al comentar, por ejemplo, que puede haber sido una inspiración para los experimentos médicos nazis que se desarrollarían años después. Hasta se ha leído en la prensa que el texto surge de dos fuentes documentales: los papeles de la Clínica Damanthal que sobrevivieron al incendio que la destruyó, y las cartas que la hermanita de Alfred le mandaba desde el hospital donde había sido secuestrada y era sometida a horribles

experimentos. Esta veracidad documental implícitamente sugerida le da a la experiencia un carácter de denuncia, con el sacudimiento de conciencia que ello provoca. El espectáculo se desarrolla en varios espacios: en el centro del escenario, entre dos telones en el fondo por donde circulan algunos personajes, en un balcón superior, en dos pequeñas vitrinas abiertas a cada lado del escenario. El cuerpo del actor - casi siempre sufriente - es el protagonista. Integrar las acciones muchas veces ralentadas, las atmósferas poéticas, y las imágenes a veces bellísimas y a veces terriblemente chocantes, que se suceden en todos estos espacios, exige la imaginación de un espectador activo.

Una nueva obra de Alejandro Catalán sigue su investigación en un tipo de teatro privilegiador de la actuación y el registro de los estados emocionales en el cuerpo del actor. Dos minas es un experimento arriesgado, 


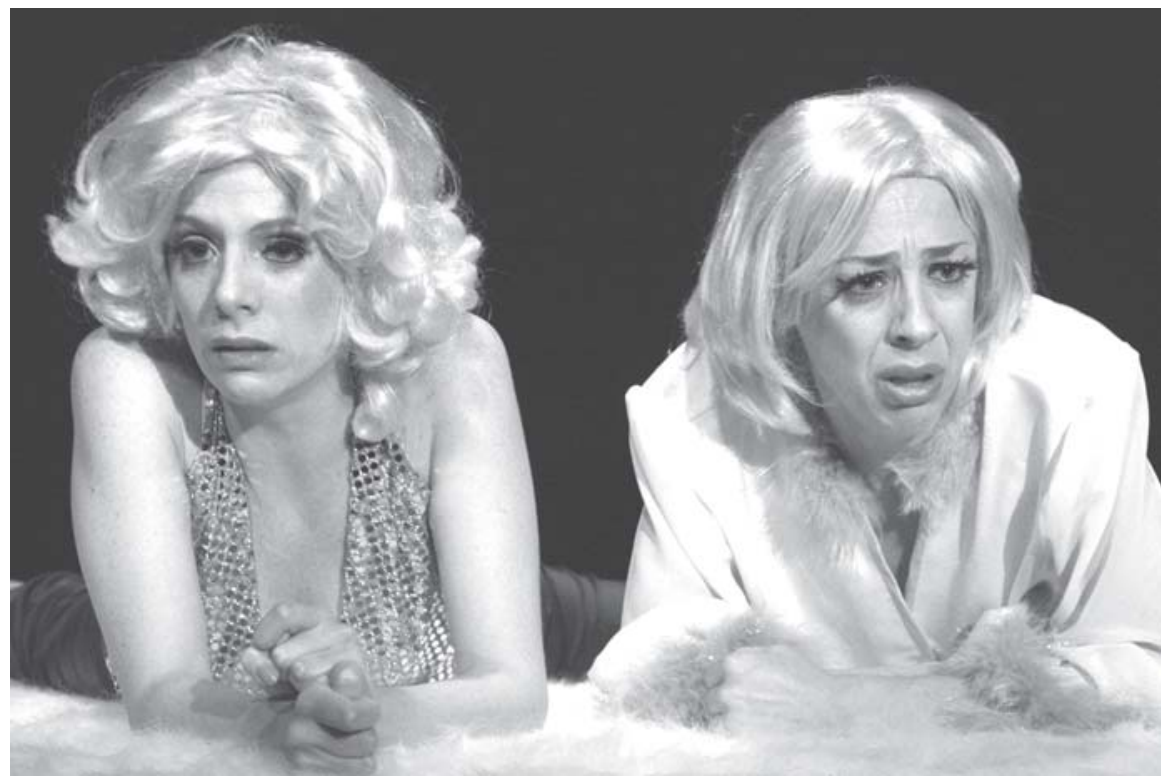

Dos minas. Foto de Silvana Miyashiki.

ya que nos pone 50 minutos frente a dos mujeres acostadas en una alfombra blanca de pelos muy largos, sin otra acción más que la conversación entre ambas, y mínimos cambios de posición, aunque siempre horizontal. Se crea así la ilusión de un primer plano cinematográfico del rostro de las actrices, ya que el resto de sus cuerpos queda en un ángulo poco visible. Todo ocurre en esos rostros y es muy interesante ver las transiciones entre estados de ánimo y los cambios de actitud. Al comienzo, domina la inercia de una noche de fin de semana, los desganados intentos por armar una salida, y el resultante no hacer nada, situación que se extiende el tiempo justo para no volverse tediosa. Luego comienzan a revelarse los conflictos que viven las dos amigas, y sobre todo la competencia y envidias entre las dos, antiguas compañeras de trabajo en una galería comercial, ahora que una de ellas está en pareja con un hombre de dinero. Las tensiones van subiendo de tono hasta la gran explosión. El texto es el resultado de un largo proceso de ensayos y otra vez Catalán se revela como un magnífico director de actores.

Parecería injusto terminar este artículo sin al menos mencionar la excelente puesta en escena de Los padres terribles de Jean Cocteau realizada por Alejandra Ciurlanti en el Teatro del Cubo. Ciurlanti es una directora nueva, que muestra un enorme talento, tanto en el uso del espacio escénico, 
como en la dirección de los actores - soberbios todos - a quienes hace transitar intermitentemente en el registro grandilocuente de la farsa. También debo referirme a la fugaz presentación de Nadar perrito, del suizo Reto Finger, en la imaginativa puesta en escena de Andrea Garrote. En ella, Rafael Spregelburd como el novio rechazado, se atrinchera en el sótano y la acción va pasando en el escenario mientras en la gran pared del fondo se ven las imágenes de video de lo que ocurre en el subsuelo. El texto, traducido por Spregelburd, es de gran calidad y pleno de humor, y las actuaciones son muy buenas, pero el hallazgo está en el uso de los espacios, alternativamente el escenario o el video del sótano. Más aún, sólo las primeras filas de espectadores en la sala del Instituto Goethe descubrieron que lo que parecía la proyección de una película realizada en otro espacio y tiempo, era la grabación en un único plano secuencia de lo que estaba sucediendo al mismo tiempo: bajo el escenario existía un sótano y veíamos la grabación simultánea de lo que allí se actuaba. Lo que parecía actuación cinematográfica (pretérita, repetida, editada) era actuación teatral (presente, única, azarosa). Por último, vale la pena mencionar una realización que se muestra a sala llena los miércoles en la pequeña sala del Espacio Callejón. Romina Paula dirigió y también es responsable de la dramaturgia de Algo de ruido hace, una original propuesta en la que se disfruta sobre todo del trabajo actoral que da vida a los dos personajes masculinos, realizado en un estilo interpretativo que adquiere en la contención su mayor riqueza. ${ }^{3}$

\section{Trinity College, Hartford, CT}

\section{Notes}

1 En junio de 2007, se estrena en los cines de Buenos Aires Final de obra, un documental de José Glusman que se centra en la creación y ensayos que desembocaron en De mal en peor. Esta película puede ser muy útil para los investigadores, ya que revela, en parte, las estrategias creativas de Bartís.

2 La mayor parte de los más exitosos intérpretes teatrales del momento se han formado con Bartís. Algunos de ellos, como Luis Machín y María Onetto, siguen actuando en teatro a la vez que se han convertido en figuras del cine y la televisión.

3 Esteban Sánchez Lamothe y Esteban Bigliardi, ambos discípulos de Catalán, otro de los principales formadores de actores en este momento en Buenos Aires. 